\title{
DEFINING A REALISTIC BALANCED SCORECARD - A BUILDING PROCESS TECHNIQUE
}

\author{
Dr. Bernard Morard, University of Geneva \\ Dr. Alexandru Stancu, University of Geneva and IATA \\ Dr. Christophe Jeannette, University of Geneva
}

\begin{abstract}
This paper examines the connection between structural equation modeling and Balanced Scorecard in a Swiss non-profit organization. Using financial and nonfinancial data taken directly from the establishment, the paper puts forward a rational construction and analysis of Balanced Scorecard by choosing the right indicators for the right strategic perspectives. This choice is made by implementing a series of Partial Least Squares in the proposed model. In addition, the method determines the cause-and-effect chain defined by Kaplan and Norton as: the measures of organizational learning and growth will impact the measures of internal business processes which in turn will affect the measures of the customer perspective which, finally, will shape the financial measures. It will be observed that the Kaplan and Norton model of Balanced Scorecard is different from the findings in this paper, a case somehow too general to cope with today's complex market environment. Subsequent to this, the study suggests a general approach to build step-by-step a realistic Balanced Scorecard rooted in the actual company's strategy. Finally, the proposed approach will be applied and evidenced in a detailed real case of a Swiss non-profit organization. (Abstract)
\end{abstract}

Keywords-(key words)

\section{Introduction}

An original model of strategic management was introduced in the early 1990s by Robert Kaplan from Harvard Business School and David Norton, co-founder and president of Balanced Scorecard Collaborative Inc., based in Boston, USA. They entitled this system the Balanced Scorecard (BSC). Identifying some of the limitations and ambiguity of earlier management systems, the BSC approach offers a comprehensible direction as to what organizations should measure in order to "balance" the financial perspective.

The Balanced Scorecard summarizes a set of measures that gives top managers a rapid but complete picture of the business. The Balanced Scorecard includes financial measures that illustrate the consequences of actions already taken and it harmonizes the financial indicators with operational measures on customer satisfaction, internal processes, and the organization's innovation and improvement activities - "operational measures that are the drivers of future financial performance" (Kaplan \& Norton, 1992).

One of the drawbacks of the BSC lies in its construction. Even though the authors give us some channeling points and explains us the steps for developing the BSC, the notions are quite vague and can be hard to put into operation in the organizational environment.
There are three objectives in this paper. The first objective is to combine the above notions and try to posit several assumptions for a realistic construction of a BSC using the Partial Least Square (PLS) technique. This is demonstrated with a nonprofit organization case where we have 94 performance indicators and 14 monthly periods for each. The performance indicators chosen will shape the different axes, and a rational explanation for this choice is developed. A cause-and-effect sequence will be engendered and clarifications made as to which latent variables (perspectives) are impacting and which are to be impacted. The second goal is to put side by side our method with Kaplan and Norton's BSC, proposing the reflection that Kaplan and Norton's model of BSC is a particular case of our conclusions. The final aim is to try to generate a realistic model that can be applied in the organization environment, thus modeling the concept of BSC.

The paper is organized as follows. In the next part, the BSC notions will be presented. The "idealistic" process of 4axes construction is then empathized pursued by a logical scheme acknowledging for the identification of the number of axes as well as the number of performance indicators associated to each perspective. This is followed by a real case of a nonprofit establishment in which the PLS technique is implemented, to create a rational BSC. At last, a tentative modeling of BSC that can be implemented in an organization environment is put forward.

\section{The call for a new validation methodology}

According to Kaplan and Norton, the BSC is a management system (not only a measurement scheme) that allows organizations to identify their vision and strategy and translate into action. Therefore the BSC grants top management a comprehensive assembly that converts the company's strategic objectives into a rational series of performance measures. It delivers response around the internal company processes as well as external outcomes in order to continuously progress strategic performance and results. When entirely deployed, the BSC translates strategic planning from a theoretical task into the central point of an organization. In Fielden's eyes (1999), organizations all over the world have begun influencing the capacity of BSC for converting vision and strategy into measurable goals.

The Balanced Scorecard can control the core of the organization's attempts, indentifying and communicating the vital key concerns to managers, employees, investors, even customers (Kaplan \& Norton, 1993). With the four 
perspectives, the BSC cut down information surplus by restricting the number of performance indicators used and forces top managers to focus on the handful of measures that are most crucial. As a result, it permits organizations to outline financial results while simultaneously observing development in structuring the capacities and obtaining the intangible assets they would need for future growth (Kaplan \& Norton, 1996). The Balanced Scorecard offers top managers with the ability to build up measures that could accurately forecast the wealth and health of an organization. By allowing the ability to translate strategy into prompt and measureable actions, a BSC coordinates strategy in an organizational environmental and tap into hidden assets and information. Additionally, by linking both internal and external people with these strategies, continual learning and development can be attained (Pineno, 2002).

Nevertheless, the BSC has problems with some of its key assumptions and relationships. First of all, there is not a causal but rather a commonsense relationship among the areas analyzed. Nørreklit (2000) argues that customer satisfaction does not automatically engender greater financial results. Measuring the financial effects of increased customer satisfaction or quality improvements requires a financial computation. Sequences of action that generate a high ratio of customer value at low costs lead to good financial outcomes. But this is not a question of causality; it is commonsense since it is inherent in the concepts. As a result, the BSC makes irrational assumptions, which may lead to the expectation of performance indicators which are inarticulate, resulting in sub-optimal performance. Moreover, the BSC is not an official strategic management tool mainly because it does not certify any relationship between organizational and environmental reality (e.g. competition). Therefore, a divergence must be accepted between the strategy articulated in the actions actually undertaken, and the strategy took into account (Nørreklit, 2000).

Within this broad-spectrum environment of criticism and uncertainty, some writers (Shields, 1997; Shields \& Shields, 1998) have called on management accounting researchers to make superior use of Structural Equation Modeling (SEM). Structural Equation Modeling is a statistical method that permits the simultaneous examination of a series of structural equations and may be considered as a family of techniques (encompassing path analysis, Partial Least Squares models and latent variable SEM). Nevertheless, there appears to be some agreement that all SEM models imply two aspects: first, the approximation of multiple interconnected dependent relations between variables, and second the capacity to represent latent variables in these relations while accounting for estimated measurement error associated with the imperfect measurement of variables. These techniques are specifically useful when a dependent variable in one equation becomes an independent variable in another equation (Hair et al., 1998).

An important issue to record is the necessity of a significant sample size for the majority of SEM models. A recommended rule of thumb for latent variable SEM is a minimum sample volume of 100 (Medsker et al., 1994). Moreover, it has further been suggested that a sample size of 200 may be needed to create valid fit measures and to avoid generating imprecise conclusions (Marsh, Balla, \& McDonald, 1988; James \& James, 1989; Boomsma, 1982; Medsker et al., 1994).

Despite these concerns, Smith and Langfield-Smith (2004) observe in one of their management researches that eleven of the 20 surveys (55\%) had sample sizes smaller than 200. Even though the recommended sample size of 100 is considered the minor bound of tolerability, three of the 20 studies (Magner, Welker, \& Campbell, 1996, Chalos \& Poon, 2000, Abernethy \& Lillis, 2001) fall below this benchmark, meaning that the conclusions pulled from these studies could be challenged.

Because of that, management accounting researchers may be discouraged from employing covariance based methods due to the considerable sample size needs, and puts forward the assertion that the technique is only suitable in areas where theory is rather strong. While these drawbacks are true for latent variable SEM techniques, Partial Least Squares (PLS) modeling offers an alternative.

Partial Least Squares regression is a relatively recent technique that generalizes and combines characteristics from principal component analysis (PCA) and multiple regressions. It is particularly helpful when needing to predict a set of dependent variables from a (very) significant set of independent variables (i.e., predictors). It was exploited in the social sciences (specifically economics, Herman Wold 1966) but became popular first in chemometrics (i.e., computational chemistry) due in part to Herman's son Svante, (Geladi \& Kowalski, 1986) and in sensory evaluation (Martens \& Naes, 1989). But PLS regression is also becoming an option in the social sciences as a multivariate approach for non-experimental and experimental data alike (neuroimaging, see Mcintosh, Bookstein, Haxby, \& Grady, 1996). It was first introduced as an algorithm similar to the power method (used for computing eigenvectors) but was quickly employed in a statistical environment (Hervé, 2003).

The use of PLS, in spite of its inherent restrictions (particularly that it is a limited-information technique, intended to maximize prediction, rather than fit), appears to be a way in which statistical modeling in management accounting study can move forward without the prerequisite to acquire large samples, something which management accounting researchers have traditionally found difficult. Another advantage of PLS is the technique's capacity to accommodate non-normal data, caused by less rigorous assumptions supporting the technique (Smith \& LangfieldSmith, 2004).

However, there is some confusion in the terminology used in the PLS field. Trying to explain it created a way to ensure the evolution of the ideas in the PLS approach. Herman Wold first developed the concept of Partial Least Squares in his study about principal component analysis (Wold, 1966) where the NILES (nonlinear iterative 
least squares) algorithm was initiated. This algorithm (and its expansion to canonical correlation analysis and to particular situations with three or more blocks) was later named NIPALS (nonlinear iterative partial least squares) (Wold, 1973; Wold, 1975).

The concept of "PLS approach" is somewhat too general and combines PLS for path models on one side and PLS regression on the other. Following a proposal by Martens (1989), this article uses the term PLS for Structural Equation Modeling to indicate the use of "PLS Path Modeling" as illustrated in Fig. 1.

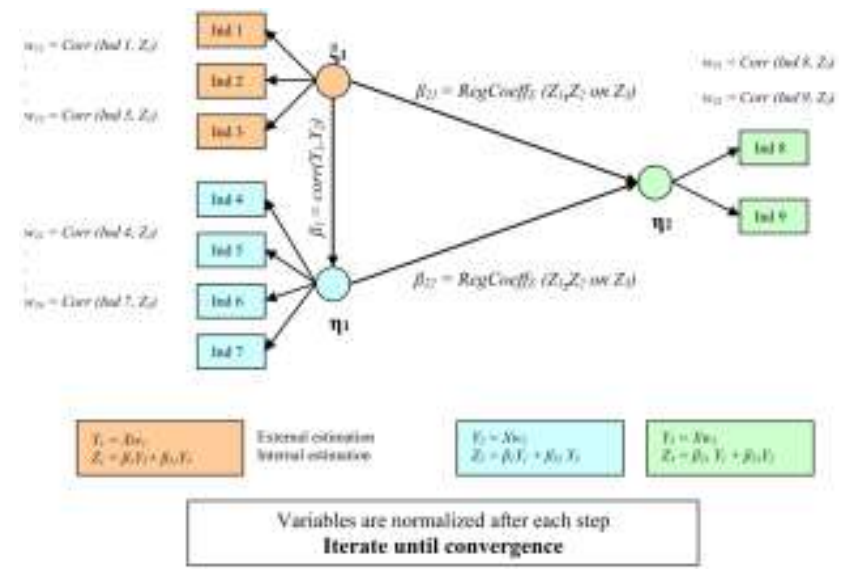

Figure 1. Example of PLS Path Modeling

Any PLS model is defined by two main relations, one between the latent variable and its manifest variables called the outer model and the other between the latent variables themselves called the inner model.

\section{Relation between the manifest variables and the latent variables (outer model)}

Each latent variable $\xi_{j}$ is indirectly defined by a group of manifest variables $x_{j h}$. Each manifest variable is connected to its latent variable by a simple regression:

$$
x_{j h}=\pi_{j h 0}+\pi_{j h} \xi_{j}+\varepsilon_{j h}
$$

\section{Relation between the latent variables (inner model)}

The causality model drives to linear equations linking the latent variables:

$\xi_{j}=\beta_{j 0}+\sum_{i} \beta_{j i} \xi_{i}+v_{j}$

The latent variables associated to $\xi_{j}$ are split into two groups: the predecessors of $\xi_{j}$ which are latent variables explaining $\xi_{j}$ and the successors which are latent variables described by $\xi_{j}$.

For a predecessor $\xi_{i}$ of the latent variable $\xi_{j}$, the inner weight $e_{j i}$ is equal to the regression coefficient of $Y_{i}$ in the multiple regression of $Y_{j}$ on all the $Y_{i}$ 's related to the predecessors of $\xi_{j}$. If $\xi_{i}$ is a follower of $\xi_{j}$ then the inner weights $e_{j i}$ is equal to the correlation between $Y_{i}$ and $Y_{j}$ (Tenenhaus \& Vinzi, 2004).

The only existing software has been for many years LVPLS 1.8 built by Lohmöller (1987, last available version). Lohmöller has extended the basic PLS algorithm in several ways and published all his research results in 1989. Lately, an updated software has been developed by Chin (2001, for the last version, still in beta test however) named PLS-Graph 3.0. It includes a Windows user-friendly graphical interface to PLSX, which is in fact the original engine for PLS path modeling existing in LVPLS 1.8. Moreover, it proposes a cross-validation of the path model parameters by jack-knife and bootstrap.

Bootstrapping is the method of estimating characteristics of an estimator (for instance its variance) by measuring those factors when sampling from an estimating distribution. One standard choice for calculating distribution is the observed distribution of the empirical data. In the case where a set of observed variables are supposed to be from an independent and identically distributed population, this can be employed by building a number of resamples of the observations (and of equal size to the observations), each of which is realized by random sampling with substitution from the original dataset. The advantage of bootstrapping over analytical techniques is its great straightforwardness - it is considerably simple to put the bootstrap into practice to find estimations of standard errors and confidence intervals for complex estimators of complex factors of the distribution, such as proportions, percentile points, odds ratio, and correlation coefficients.

Nevertheless, a deeper analysis of the PLS Path Modeling allowed us to build our software from scratch in order to compute the path weighting scheme and the bootstrap technique validation.

\section{CONNECTING BALANCED SCORECARD WITH PARTIAL LEAST SQUARES}

Ittner and Larckner advise that "(...) decisions using multicriteria performance measurement systems should be computed using explicit, objective formula that prescribes the weights to be attached to each measure, or should be based on subjective evaluations where the weights to be attached to each measure is implicitly or explicitly chosen by the decision maker" (Ittner \& Larckner, 1998). This should be taken into consideration in order to build, check and validate assumptions of causality relations between the indicators within the framework of the implementation of BSC in an organization, while following the application of a PLS technique.

The original assumptions of causality relations between the four latent variables of the Kaplan and Norton BSC, illustrated by the four perspectives in Figure 2, remain subjective. The employ of a structural equations model is recommended to show, in a more objective way, the strength 
of the links between the latent variables expressed by sets of measurable indicators. Certainly, whereas the selection of the perspective and the assumptions that bind them remain subjective, the model of structural equations intends "to provide a meaningful and parsimonious explanation for observed relationships within a set of measured variables" (MacCallum, 1995).

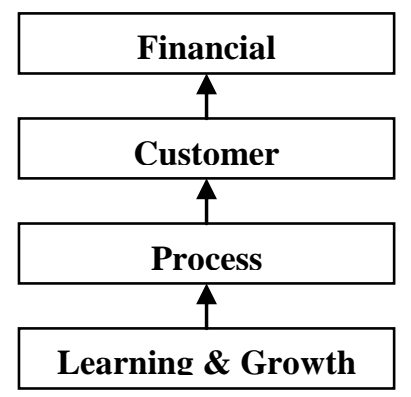

Figure 2. Generic relationship map (Kaplan and Norton 1996)

In a system of structural equations we would find latent variables that cannot be measured directly and accurately. Therefore, these latent variables need measurable variables, which are defined through performance indicators that can be directly observed and measured. The technique of structural equations is based on the principal component analysis (exploratory or confirmatory, according to the specific case) of the data to identify and validate the model of the causal relations which constitute the architecture of BSC. It is imperative to underline that one of the limits inherent in the application of a system of structural equations in the context of BSC, is the prerequisite statistics needed for the data standardization, which requires an important quantity of observations in order to confidently validate the results obtained. The collection of a great sample of data is not obvious, especially in small and medium-sized companies. This is why the application of the PLS is better in this particular case or in any case where significant data is available.

\section{Iv. A PRAGMATIC CASE: Example of a non-profit organization}

The method proposed in this research is presented using an example of a non-profit organization. To ensure data protection, the name of the organization, as well as some of its services, were camouflaged. The analyzed organization is a non-governmental, non-profit, health-services type of institution that promotes ways to inform, identify, prevent and cure in some cases a particular class of diseases.

The idea of using PLS approach in order to analyze the measures of performance, translated into BSC, will permit the following:

- Enhanced decision-making for resource reallocation with the help of performance simulation of the selected strategy;

- Improved communication within the company of this performance;
- Anticipation of new strategic performance indicators.

In brief, there are five chronological main steps in our proposed methodology that will allow us to construct and put into practice a rational and optimal BSC: (1) collect data from the organization, (2) clean and prepare the final database, (3) establish and define the numbers of perspectives and performance indicators related to those, (4) build the cause and effect chain between strategic perspectives and, finally, (5) use and manage the tool for long-term vision.

As illustrated in Figure 3, the first step is related to gathering all historic key performance indicators throughout the company. As this might seem an easy task, it involves a tremendous time harvesting the indicators used in the company, especially creating a stable historic base. This part is very important and will considerably condition all of the following steps. A total of 148 quarterly key strategic indicators have been collected throughout the whole organization summarizing 16 time periods (quarters).

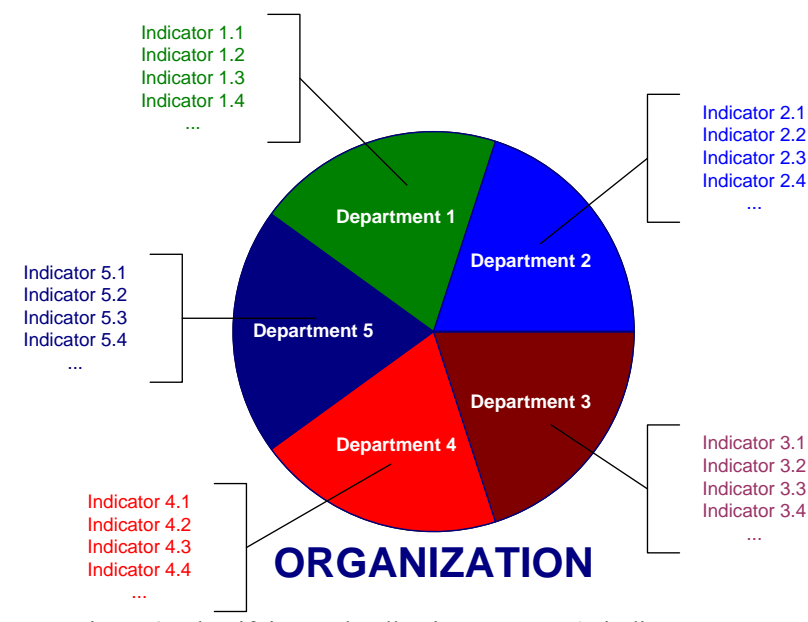

Figure 3. Identifying and collecting company's indicators

Because of the large initial database of performance indicators, the second step is related to the need of a cleaning of data that could contain noise, polluting the final result (Figure 4). As mentioned before, the indicators gathered are affecting the findings. Therefore the data should be characterized by (a) reliability and consistency, (b) same frequency and availability in time, (c) capability to capture a portion of the company's actual strategy, (d) information singularity and (e) easiness of use and clarity. After a rough analysis and intense top management interviews, the final database from our non-profit organization case was reduced to 94 key performance indicators. These indicators were considered to be the chief drivers in the organizational overall strategic analysis. 


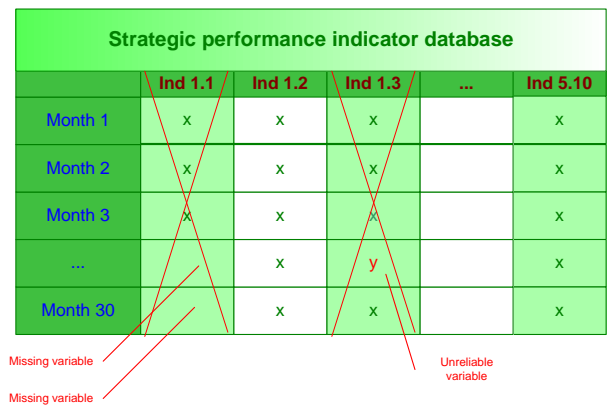

Figure 4. Example of cleaning and arranging the final database

However, even if this commonsense managerial filter has been applied, the organization still has a considerable database which is quite difficult to manage for the BSC construction. Also portrayed in Figure 5, the third main step is to regroup and filter the indicators within specific axes (or strategic perspectives) that can summarize a portion of the company's information.

There are three major achievements by doing that: first is to generate groups of indicators that are correlated to strategic axes, second is to filter each axis and keep only the indicators that are strongly related and putting apart any redundant and insignificant information and third is to name these groups (or axes) by analyzing the type of information that gravitates each axis.

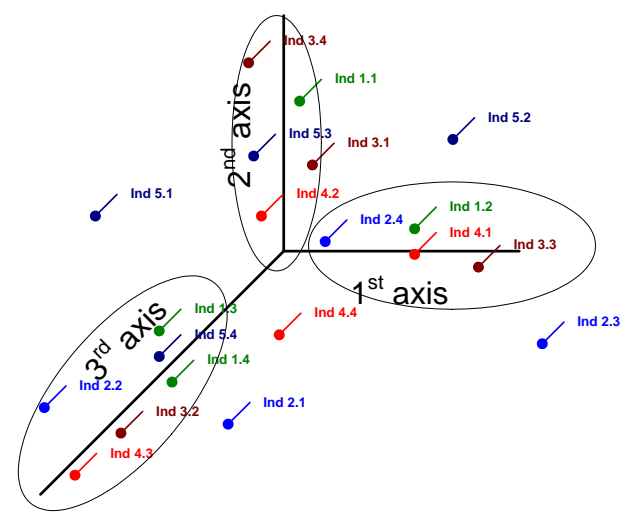

Figure 5. Filtering the performance indicators per strategic perspectives

There are few existing statistical techniques in order to achieve this classification. Both factor analysis and principal component analysis (PCA) can be used for this scope. Principal component analysis can be employed for dimensionality reduction in a data set by maintaining those features of the data set that contribute most to its variance and by retaining lower-order principal components and ignoring higher-order ones. Such low-order components usually capture the "most important" characteristics of the data. Factor analysis on the other hand, is a statistical method applied to explain variability among studied variables in terms of fewer unobserved variables named factors. Factor analysis helps to identify "factors" that describe a variety of results on different tests.

Nevertheless, the PCA fits better our requirements as it is suited for a non-predefined experimental model, whereas factor analysis is better for models that have already a guideline. Factor analysis is often mixed up with principal components analysis. The two techniques are connected, but different, though factor analysis becomes basically equivalent to PCA if the "errors" in the factor analysis model are assumed to all have the same variance.

As the statistical model applied (PCA) is using historical data, the result of the actual research will consequently depend on the data available at the time of collection. However, the objective of this illustration is not to develop the best indicators, which sometimes could conduct to subjectivity and personal choice, but to actually highlight the relevance of the variables available.

The software employed for the PCA computation was SPSS. After this step is completed over the whole database, one can easily remark that with 6 components, merely $78 \%$ of the total organizational variance is explained (Table 1). This percentage could be translated by the influence of the axes on the total performance: the higher this percentage, the more explanation it gives on the performance.

TABLE 1. EXTRACT OF TOTAL VARIANCE EXPLAINED

\begin{tabular}{|c|c|c|}
\hline Component & \% of Variance & Cumulative \% \\
\hline 1 & 27.17 & 27.17 \\
\hline 2 & 17.08 & 44.25 \\
\hline 3 & 12.38 & 56.63 \\
\hline 4 & 10.55 & 67.18 \\
\hline 5 & 5.70 & 72.88 \\
\hline 6 & 5.09 & 77.98 \\
\hline
\end{tabular}

The same PCA analysis also gives the variables (indicators) influencing each of these 6 axes with the help of the component matrix determining the correlation of each variable with the selected axes. Table 2 visualizes the correlation of the first 10 variables with each axis. The closer a correlation is to 0 , the less the corresponding variable influences the axis. The data will be sorted and filtered with respect to the influence is has upon the axes. In principal, a variable will be associated with the axes it influences the most (which is given by the absolute value of the correlation).

The sorting by axis makes possible to name and define them strategically. For that, the first 10-15 indicators per axis are preferable for selection, sorted by their correlation with the axis. First, this number of indicators gives a good visibility of the information grouped by the axis and second, as the indicators are sorted by their correlation, the indicators will be less and less correlated with the axis, thus their explanatory value will decrease. One can remark that this simple selection will group the indicators that are specific to one area of the company. That is to say, a simple mathematical grouping will sort out the actual areas specific to the company. 
TABLE 2. EXTRACT OF THE FIRST 10 INDICATORS FROM THE COMPONENT MATRIX

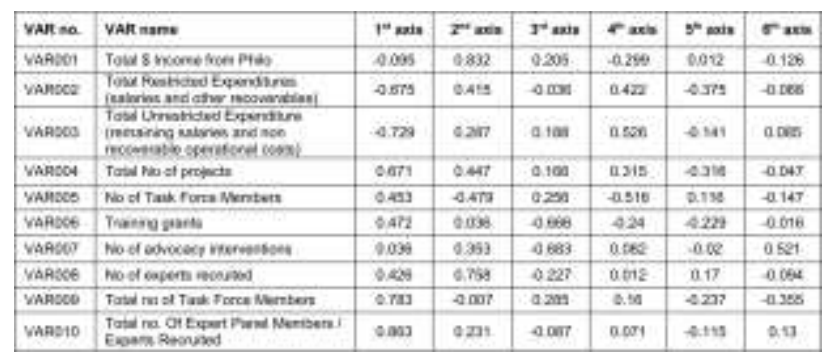

That being done, one still needs a small grooming of the data by removing those indicators which would not sufficiently explain the definition given of the axis. Though this step it is not mathematically justified, it is mainly intended to clear certain data that is not rigorously exact and would pollute the definition of the axis. The exclusion of the variable must be well explained in light of the strategy for defining the statistical axes. In any economic environment (which by definition is uncertain) it is rather difficult (even impossible) to find only the indicators correlated to the perspective in the cause. Statistically speaking, several indicators could be highly correlated to one axis. However, from a practical point of view these indicators do not represent the axis and will corrupt the final result. These indicators should not be selected as being representative for the final model as they do not describe the definition of the majority for that axis.

However, due to a very low correlation of indicators with the final axis on one hand and inconsistency in explaining the indicators linked with this axis on the other hand, it has been decided to completely remove the 6th axis from this analysis. With only five axes, one can notice that the total variance of the company is explained to almost $73 \%$, being more than enough to extrapolate to the overall strategy of the organization.

In order to be able to control and understand the final model, to keep a certain precision of the axes and leaving aside indicators that will not bring in much explanation value, the final number of indicators per axis should not exceed six or seven. At the end of this third step, the following strategic perspectives have been identified: Quality, Learning and Growth, Internal Processes, Finance and External (Stakeholder) Impact each of them with 4 to 7 explanatory variables as explained in the next step.

As illustrated in Figure 6, the fourth major step in finding out the actual strategy of the organization is to implement a PLS Path Modeling regression on the final and selected strategic perspective. To find out the most viable cause-and-effect chain between the axes, all possible valid connections between the axes should be analyzed. The most stable PLS model from all of the above combinations is considered to be the closed to the company's actual strategy.
The stability of the PLS model could be determined using the bootstrap technique on each possible graph.

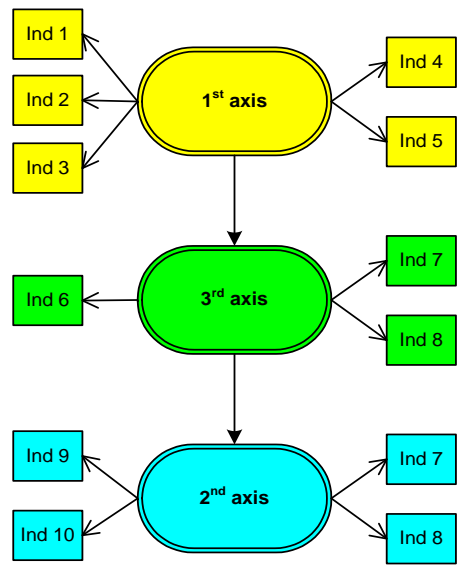

Figure 6. Exemplification of a cause-and-effect chain using PLS Path modeling

Applying this step to our specific case, all possible valid connections between the 5 axes, that is to say a total number of 52'720 possibilities were analyzed with the software created specifically for this study and the most stable PLS model was selected from all of the above combinations represented in Figure 7.

We could state that this arrangement is the optimal structure of connections between the five axes. This logical chain appears more realistic than any other model and closer to the present organizational strategic vision.

First thing to notice is that Learning and Growth and Internal Process perspectives are situated at the bottom of the chain, similarly to the original Kaplan and Norton BSC, where the measures of organizational learning and growth will positively impact the measures of internal business processes. However, the Internal Process perspective negatively impacts the Finance one. This is explained by two reasons. First, by analyzing the performance indicators from the Internal Process axis (trainings, advocacy interventions, Cybercenter), it is rational that more stress is put into it the more financial indicators are impacted. Second, it was well known that the organization is facing poor financial management since several years. Moreover, Finance perspective also negatively impacts both the Stakeholder and Quality axis. This means that when more focus is placed over organizational investments a compromise is made to the other axes. Realistically, the major stakeholders were unhappy with the quality offered by the organization, taking into consideration the investments propelled recently. It should be also noticed the positive link between the stakeholders versus quality perspective. Indeed, the more emphasis is placed on fellowship scheme offered, external conferences and Globalink (one of the main services offered by the organization), the more positive influence is granted to Quality. 


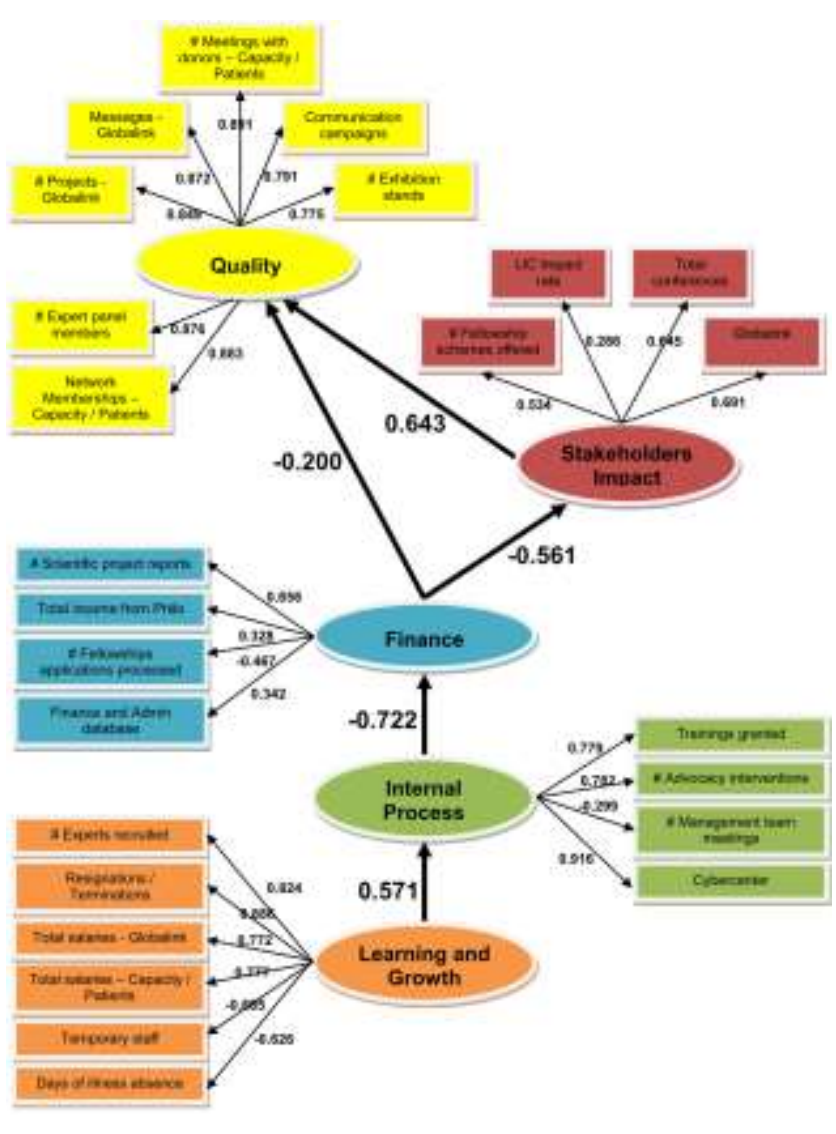

Figure 7. BSC's cause-and-effect chain using PLS approach (with 16 quarterly time periods)

When it comes to model validation (Table 3), the overall figures are relatively good, assessing in a good way both measurement (outer) and structural (inner) model. As a general thumb, the Average variance Explained (AVE) should be above 0.5 (Chin, 1998) and Composite reliability greater than 0.6 (Werts, Linn, and Jöreskog, 1974) in order to accurately validate the outer model (measurement model). One can remark a poor validation for the Finance perspective, but this could be partially explained by the 3 indicators that have quite low loading factors $(0.328,-0.467$ and 0.342 respectively).

TABLE 3. PLS MODEL VALIDATION CRITERIA

\begin{tabular}{|c|c|c|c|c|}
\hline & AVE & $\begin{array}{c}\text { Composite } \\
\text { reliability }\end{array}$ & R-square & $\begin{array}{c}\text { Redundancy } \\
\text { index }\end{array}$ \\
\hline Finance & 0.218 & 0.191 & 0.522 & 0.112 \\
\hline $\begin{array}{c}\text { Learning and } \\
\text { Growth }\end{array}$ & 0.587 & 0.605 & & \\
\hline $\begin{array}{c}\text { Internal Process } \\
\text { Quality }\end{array}$ & 0.537 & 0.719 & 0.396 & 0.161 \\
\hline $\begin{array}{c}\text { Stakeholder } \\
\text { Impact }\end{array}$ & 0.515 & 0.629 & 0.354 & 0.100 \\
\hline
\end{tabular}

As for structural model assessment, the best gauge to use is the R-square level. Values of $0.67,0.33$ and 0.19 are considered to be strong, moderate and respectively weak for the inner model valuation (Chin, 1998). The R-square have acceptable values for Internal Process and Stakeholder axes and substantial levels for Finance and Quality axes, altogether validating in a satisfactory way the inner model.

As noted in the first part of the study, the inner and outer relations are based on structural equations. Therefore, behind each PLS Path model lies equations that explains the relations between indicators with the corresponding axis (outer model) and between the axes or strategic perspectives (inner model). The fifth major step is to apply these equations in order to study the relations between the items for the long term. From a practical point of view, there are significant advantages by doing that:

a) analyzing the variance of one (or several) indicators to the whole model;

b) forecasting the strategic changes by looking at the relationships between the axes;

c) the direct and indirect changes needed for an important change in the company strategic vision;

d) simulate the impact of resources allocation decisions on the strategic performance (why not substituting the budget with this approach for next years);

Exemplifying this step with the current pragmatic case, we were able to reproduce the PLS model with 4 additional datasets (one year). Although the fourth step has been completely redone, no major changes have been highlighted in the current strategy, as one can easily remark from Figure 8. The positive aspect of this finding is that the methodology proposed is further confirmed emphasizing the stability of our optimal model. However, on the negative side, we observe no key adjustments taken by the organization in order to recalibrate to the actual global crisis situation, even if a complete proposition has been made, based on the PLS analysis and in collaboration with the top-management. In addition, this outcome highlights the fact that a change in an organization strategy cannot be done in a rapid and unreflected way. Moreover, one has to keep in mind that a non-profit organization cannot be revolutionized or radically transformed as a commercially-driven company might be. Nevertheless, this example reinforced our findings posed in the beginning of the study. 


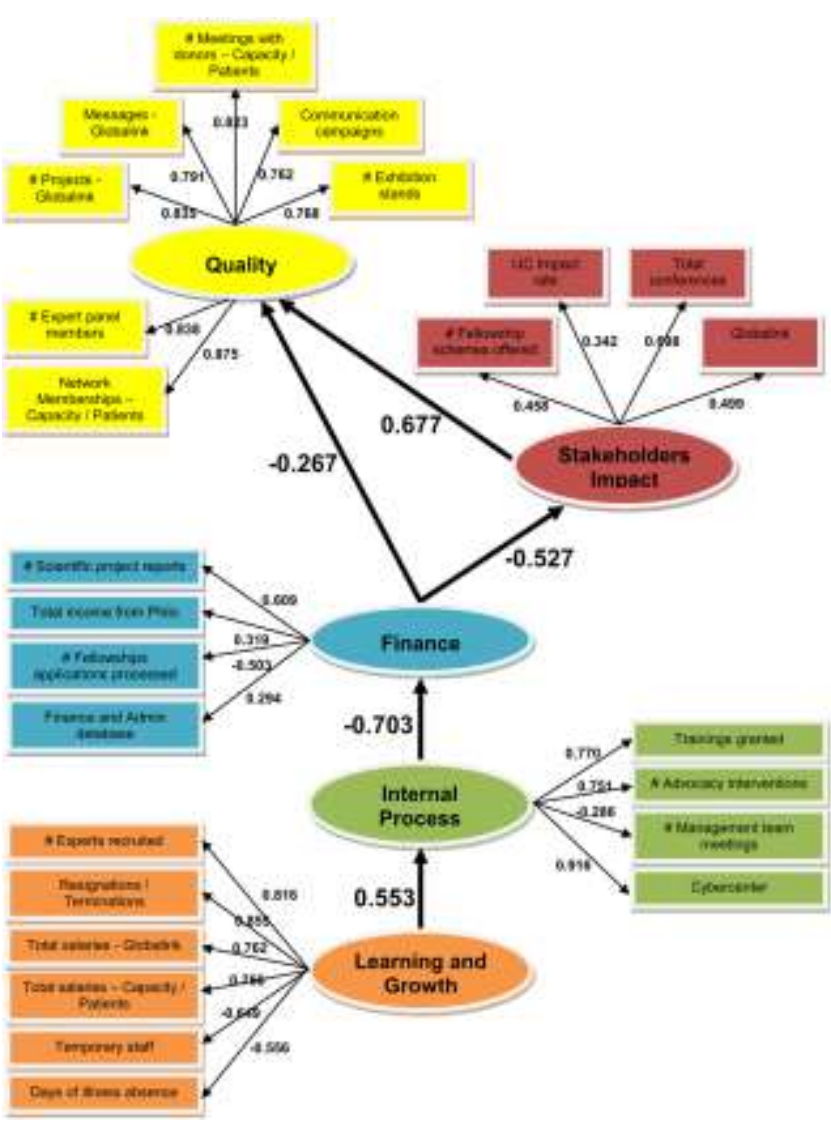

Figure 8. BSC's cause-and-effect chain using PLS approach (with 20 quarterly time periods)

\section{v. CONCLUSIONS AND REMARKS}

The key part in the PLS technique is the choice of the axis and of the corresponding performance indicators. If the aim of the study is the strategy, then it is necessary that the key performance indicators describe it well.

This leads us to the decision to filter out the essential constituents for defining the strategy with respect to the chosen level of analysis. Undeniably the measures of the strategy for an organization or a sector do not have the same performance indicators as one of another sector (e.g. manufacturing company).

The research goal of this study was to develop and empirically validate a comprehensive research framework that bridges Balanced Scorecard model and Structural Equation Modeling approach and promotes a state-of-the-art understanding of factors underlying, in order to better manage and control the corporate performance.

The first important step towards this objective was the development of a common frame of reference that harmonized hitherto conflicting theoretical assumptions related to Balanced Scorecard ease of implementation. Based on this foundation, we proposed a framework for strategic analysis embracing three major concepts. The proposed model:

1. addresses the problem of strategic vision of any company and translates the current strategy into an easy-to-use structure for better integration, communication and long-term management;

2. highlights the utmost performance indicators that have the capacity to capture the most relevant information from the company, information that is strongly linked to the actual objectives the company is aiming for;

3. assembles distinct strategic perspectives that summarizes company information in a convenient way, in order to generate an all-inclusive representation driving organizations in their road to success;

4. establishes the best relations between strategic perspectives in a cause-and-effect link that emphasizes the interactions taking place at the strategic level, helping in this way to better understand and spotlight the company's advantages and weaknesses;

5. Overcomes the static character of prior models dealing with some of the dynamic evolution over time by implementing mathematical equations between performance indicators and the strategic perspectives, improving the forecast and control of the main elements within a company.

Having established the strategic research framework, we attempted to empirically test the proposed model in the context of the one nonprofit organization. This approach makes it possible to simulate the impact of a resource allocation decision on the strategic performance.

The main purpose of this study has been to put in perspective the BSC in the debate between Kaplan and Norton theory and a more pragmatic approach. A strategic chart has been developed for a non-profit organization. The robustness of this model has been tested through the analysis of the links' validity among the perspectives using the bootstrap technique. With this intention, the SPSS software was used along with and a PLS software built specifically for this study. The results obtained showed that the reasoning of BSC postulated in the problems can be formalized in a rigorous way. It is thus possible to reconsider the remarks advanced by Kaplan and Norton as shown in the analysis of the case. This illustration provides, using the PLS software, a theoretical framework for a pragmatic approach. It should be stressed that the conditions necessary to arrive here are relatively constraining. In general, it is necessary to have sufficient number of indicators being used for estimating each perspective while respecting postulates such as normality or removing the strong correlation between the indicators. Then, it is essential to have a relatively viable and important sample of data. Moreover, the noted real use of BSC lies more in the diffusion and the comprehension of the strategy on all the levels within the company.

The PLS Path modeling converts the actual vision into strategic perspectives, that can be managed and observed by different performance indicators. One might argue that by using historical data, the model summarizes and explains 
obsolete information that it goes way too much in the past. While the supposition is correct, the model is actually describing the current strategy implemented by the organization. And not only the current one, but, as the PLS regression is more suited for maximize prediction, it also portrays the forecast vision of the organization. It is also true that these tools are applied in a moment of a significant strategic change in the company. The use of this approach allows not only understanding the chain of causality of the strategically performance, but also reinforcing intuition by "a measure of the measures".

To conclude, we think that it would be relevant to develop a tool making it possible to formalize and to validate the strategy in a theoretical way, while using a simplified model. The PLS method suffers from a lack of theoretical base. Similarly, Kaplan and Norton's approach was strongly criticized in the literature from this point of view as well. The difficulty with which future researchers will be confronted lies in the reconciliation between the pragmatism sought by the institutions and the need for the theoretical framework.

\section{References}

[1] G. Eason, B. Noble, and I. N. Sneddon, "On certain integrals

[2] Abernethy, M.A., \& Lillis A.M. (2001). Interdependencies in organization design: A test in hospitals. Journal of Management Accounting Research, 13,107-129.

[3] Boomsma, A. (1982). The robustness of LISREL against small sample sizes in factor analysis models. In K.G. Joreskog and H. Wold (eds.), Systems Under Indirect Observation: Causality, Structure, and Prediction, Part I, 149-173. Amsterdam: North-Holland Publishing.

[4] Chalos, P., \& Poon, M.C.C. (2000). Participation and performance in capital budgeting teams. Behavioral Research in Accounting, 12, 199229.

[5] Chin, W.W. (1998). The partial least squares approach to structural equation modeling. Modern Methods for Business Research, 295-336.

[6] Fielden, T. (1999). Pilot Refines Decision Support. InfoWorld, November 29, pp. 77-78.

[7] Geladi, P., \& Kowalski, B.R. (1986). Partial least squares regression: A tutorial. Analytica Chimica Acta, 185, 1-17.

[8] Hair, J. F. Jr., Anderson, R. E., Tatham, R. L., \& Black, W. C. (1998). Multivariate data analysis with readings (Fifth Edition). Upper Saddle River, NJ: Prentice-Hall International.

[9] Hervé, A. (2003). Partial least squares (PLS) regression. In LewisBeck, M., Bryman, A., Futing, T. (Eds.), Encyclopedia of Social Sciences Research Methods. Thousand Oaks (CA): Sage

[10] Ittner, C. D., \& Larcker, D. F. (1998). Innovations in performance measurement : Trends and research implications. Journal of Management Accounting Research, Vol. 10, 205-239.

[11] James, L.R., \& James, L.A. (1989). Causal modeling in organizational research. In C.L. Cooper, and I. Robertson (eds.), International Review of Industrial and Organizational Psychology, 371-404. New York: John Wiley.

[12] Kaplan, S. R., \& Norton, P. D. (1992). The Balanced Scorecard: measures that drive performance. Harvard Business Review, January - February, 71-79.

[13] Kaplan, S. R., \& Norton, P. D. (1993). Putting the Balanced Scorecard to work. Harvard Business Review, September - October, 142-143.

[14] Kaplan, S. R., \& Norton, P. D. (1996). Using the Balanced Scorecard as a strategic management system. Harvard Business Review, January - February, 75-85.

[15] Kaplan, S. R., \& Norton, P. D. (1996). Linking the Balanced Scorecard to strategy. California Management Review, Fall, 53-79

[16] Martens, H., \& Naes, T. (1989). Multivariate Calibration. NY: Wiley.
[17] MacCallum, R. C. (1995). Model specification: Procedures, strategies and related issues. In R. H. Hoyle (ed.), Structural Equations Modeling, Thousand Oaks (CA): Sage, 16-36.

[18] Magner, N., Welker, R.B., \& Campbell, T.L. (1996). Testing a model of cognitive budgetary participation processes in a latent variable structural equations framework. Accounting and Business Research, 27, 41-50.

[19] Marsh, H.W., Balla, J.W., \& McDonald R.P. (1988). Goodness-of-fit indices in confirmatory factor analysis: Effects of sample size. Psychological Bulletin, 103, 391-411.

[20] McIntosh, A.R., Bookstein, F.L., Haxby, J.V., \& Grady, C.L. (1996). Spatial pattern analysis of functional brain images using partial least squares. Neuroimage, 3, 143-157.

[21] Medsker, G.J., Williams, L.J., \& Holahan P.J. (1994). A review of current practices for evaluating causal models in organizational behavior and human resources management research. Journal of Management, 20, 439-464.

[22] Nørreklit, H. (2000). The balance on the Balanced Scorecard - a critical analysis of some of its assumptions. Management Accounting Review, 11.

[23] Pineno, C. C. (2002). The Balanced Scorecard: an incremental approach model to health care management. Journal of Health Care Finance.

[24] Shields, M. (1997). Research in management accounting by North American in the 1990's. Journal of Management Accounting Research, 9, 1-61.

[25] Shields, J. F., \& Shields, M. (1998). Antecedents of participative budgeting. Accounting, Organisations and Society, 23, 49-76.

[26] Smith, D., Smith, L.K. (2004). Structural equation modeling in management accounting research: critical analysis and opportunities. Journal of Accounting Literature, 23, 49-86.

[27] Tenenhaus, M., \& Vinzi, V.E. (2005). PLS Path Modeling. Computational Statistics and \& Data Analysis, 48(1): 159-205.

[28] Wold, H. (1966). Estimation of principal components and relazed models by iterative least squares. In P. R. Krishnaiah (ed.). Multivariate Analysis: Preceeding of International Symposium held in Dayton, Ohio, June 14-19, 1965, 391-420, New York: Academic Press.

[29] Wold, H. (1973). Nonlinear iterative partial least squares (NIPALS) modeling: Some current developments. In P.R. Krishnaiah (ed.). Multivariate Analysis II: Preceeding of an International Symposium held at Wright State University Dayton, Ohio, June 19-24, 1972, 383407, New York: Academic Press.

[30] Wold, H. (1975). Path models with latent variables: The NIPALS approach. In H.M. Blalock, A. Aganbegian, F.M. Borodkin, R. Boudon, \& V. Cappecchi (Eds.), Quantitative Sociology: International Perspectives on Mathematical and Statistical Modeling, 307-357, New York: Academic Press.

[31] Wold, H. (1986). Partial least squares. Encyclopedia of Statistical Sciences, Vol. 6, New York: Wiley. 